Journal of Economic Theory 5 (1): 22-27, 2011

ISSN: 1994-8212

(C) Medwell Journals, 2011

\title{
Some Reflections on the Determinants of Sectoral Disarticulation
}

\author{
Philip O. Sijuwade \\ School of Urban and Public Affairs, University of Texas, Arlington, Texas
}

\begin{abstract}
Disarticulation, a concept coined by Samir Amin to describe uneven sectoral development has been shown to stand in the way of the progress in human welfare that is frequently associated with economic development. This study offers a quantitative assessment of dependency and conventional modernization accounts of why disarticulation comes into being. Results from cross-sectional analyses set in 1965 show that higher levels of disarticulation are associated with national extraversion and urban primacy. Results from a panel regression analysis between 1965 and 1990, however suggest that changes in disarticulation may be the predictable result of normal economic development with early development being associated with increases in sectoral disarticulation and later development with decreases in disarticulation.
\end{abstract}

Key words: Economic development, disarticulation, regression analysis, human welfare, assessment, Texas

\section{INTRODUCTION}

A not so recent literature (Stokes and Anderson, 2000; Huang, 1995) has arisen around the concept of sectoral, economic or structural disarticulation. Firmly rooted in Amin $(1974,1976)$ 's version of dependency, disarticulation has been used to account for the slippage in the association between economic growth and the improvement of social welfare that was expected by early development planners during 3rd World development. Thus, sectoral disarticulation has been shown to have an adverse effect, net of the effects of economic development, on child mortality, crude death rates, educational enrollment (Huang, 1995) on a summary index of human development (Huang, 1995) and on fertility rates (Stokes and Anderson, 2000).

These effects are so strong that all who have written about disarticulation agree that it is time to look more carefully at reasons why sectoral disarticulation itself comes into being.

\section{THEORY ABOUT THE CAUSES OF SECTORAL DISARTICULTION}

The dependency theory version: The concept of sectoral disarticulation has been used to account for the lack of an anticipated correspondence between economic growth and social progress. How can it be, asks Huang (1995) that Brazil with a GNP per capital of $>\$ 2000$ and Sri Lanka with a GNP per capital of $<\$ 400$ have drastically different levels of development, yet Sri Lanka has achieved a high level of human development comparable to that of Brazil. One answer has been that some economies, though relatively productive by conventional economic measures are not particularly well integrated or articulated. As a result, despite overall economic productivity, wealth is poorly distributed and relatively ineffective at increasing overall human welfare. An example from today's news is mainland China with its booming economic growth but with a growth so confined to coastal cities so foreign to inland rural areas that China's leaders worry about the implicit threat to the nation's political stability. According to Amin (1974, 1976), the theorist who coined the term, disarticulation exists when an economy consists of economic sectors with very different levels of productivity or more precisely, profitabilities.

Although, recent operational definitions of disarticulation have varied they have all compared the percentage distribution of the labor force to the percentage distribution of national product in the major sectors of a nation's economy. An economy with virtually all its people working in the agricultural sector but virtually all its national product being generated in the manufacturing sector for instance, would be extremely disarticulate. One can easily imagine why the benefits of increasing national product would not be translated into increasing human welfare in such an economy. In the absence of a powerful, redistributive state, only a tiny fraction of the population would be connected to profitable activity.

Why do economies become disarticulated? Amin suggests that the major cause of disarticulation is extraversion or an economic orientation to the outside world which comes from a dependence on foreign markets and capital. Such an external orientation, especially in less developed economies is apt to lead to the modernization of sectors that are linked to foreign markets by trade and 


\section{J. Econ. Theroy, 5 (1): 22-27, 2011}

capital, making them more profitable. Simultaneously however, unlinked, traditional sectors become comparatively unprofitable. The issue of linkages is believed to be especially problematic in the case of extraversion, since the new industries are likely to focus on external markets and hence be less likely than they otherwise would be to supply inputs to other industries within the domestic economy (forward linkages) and/or to demand such inputs from such industries (backward linkages).

While extraversion may be the driving force behind disarticulation in less developed economies, other structural conditions may mediate extraversion's direct effect on disarticulation. The structure of a nation's urban system for one thing would seem to have such a mediating effect. Thus, Stokes and Anderson (2000) suggest that the elephantine cities of the 3rd world become the focus of aspirations for a better life, attracting craft persons and rural workers dispossessed or made redundant through extraversion. This is not the 1 st time, elephants have been confused with what have been traditionally called primates in comparative urban studies (Jacobs, 2004). But the idea that disproportionately large urban centers or primate cities have been the product of what Amin refers to as extraversion has long been a dominant theme in the dependency literature. A rural collapse explanation of urban primacy, for instance suggests that major primate cities which during early dependency may have had counterparts in slightly smaller provincial centers become the major targets for surplus population in later dependency. Stokes and Anderson suggest that these cities act as magnets for refugees from relatively unproductive rural areas and smaller urban places.

Moreover, they imply that the primate cities become the locus of an increasingly hypertrophic tertiary sector. This means that the presence of primate cities may itself be a source of unusual disarticulation.

A conventional modernization version: I am not aware of a conventional modernization account of what Amin defined as disarticulation per se. Still, a literature deriving from Kuznets (1955)'s early work relating economic development to income inequality has employed a concept, dubbed sectorial dualism that while not a precise cognate of disarticulation has been explained in ways that promise alternative views of disarticulation's etiology. Sector dualism is generally used to refer to the amount of income inequality due to the income differences between traditional and modern sectors or labor-intensive and capital-intensive sectors in developing economies (Nielsen, 1994; Ballmer-Cao, 2009). In the aforementioned literature, sector dualism is often operationalized as productivity differences between a (traditional) agricultural sector and a (modern) industrial sector that favor the latter. Nielsen (1994) argues that any variable (such as education or modernization) associated with industrialization that diffuses unevenly across the population can generate its own dualism but those who have focused on sector dualism have tended to focus on relative amounts of capital invested in each sector and demographic variables like the level of agricultural employment.

Early development in the Kuznets (1955) tradition, generally refers to industrialization and urbanization that result from the creation of relatively capital-intensive, non agricultural industries. This early concentration of capital-intensive, increasingly productive industry in urban areas naturally leads to an increase in the comparative productivity of agriculture. Hence, a rise in sectoral dualism and sectoral disarticulation if the argument may be extended to disarticulation among several, rather than just two sectors. Where capital comes hardly matters as its source, capital is initially invested unequally in various economic sectors.

Consequently, some of those sectors become more productive than others. But since (sectoral) productivity is a function of both labor and capital, one must theorize about what happens to each of these as development proceeds. Lecaillion (2004) imply that disparities in sectoral productivity will decline in so far as labor successfully transfers itself from less productive sectors to more productive ones. This is frequently achieved by rural-urban migration but in any case by movement out of less productive sectors. According to Lecaillion, such movement typically involves a decline in agricultural employment. To see how subsequent inputs of capital after early development may affect sectoral disarticulation, one may simply reverse the order of cause and effect implied by recent dependency theorizing.

This theorizing suggests that disarticulation may stand in the way of the usual domestic multiplier and accelerator effects associated with development. But suppose that early disarticulation as suggested above is the result of investment in a limited number of economic sectors, invested in activities that may provide local inputs for increased production. In such a scenario, one can well imagine that capital investment (perhaps whether it comes from domestic or foreign sources) beyond a certain point will act to reduce disarticulation by spreading capital more evenly over economic sectors. The foregoing discussion suggests at least four hypotheses about the development of sectoral disarticulation. From the dependency literature, one comes to expect: 
Hypothesis 1: The greater a developing nation's extraversion, the greater its sectoral disarticulation.

Hypothesis 2: The greater a developing nation's level of urban primacy, the greater its sectoral disarticulation.

From the conventional development literature, one comes to expect:

Hypothesis 3: Sectoral disarticulation will increase and then decrease with normal development.

Hypothesis 4: Sectoral disarticulation is a positive function of the portion of the labor force in agriculture and a negative function of its decline over time.

\section{MATERIALS AND METHODS}

Sectoral disarticulation: Two previous efforts to measure sectoral disarticulation have been made. Stokes and Anderson (2000) measured it in terms of the sum of absolute differences between the percentage of distribution of the labor force and the percentage of distribution of national income over seven economic sectors. Huang (1995) pointed out that a flaw in this measure is the inability of researchers to interpret it in terms of the key element of the disarticulation's conceptual definition; the comparison of one economic sectors's productivity per worker with that of other economic sectors. Huang proposed an operational definition that does indeed, capture this critical element; the totality of deviations of productivity per worker of each economic sector from the average productivity per worker in the overall economy.

Extraversion: Extraversion is normally conceptualized as the degree to which a nation's economy relies on outside trade or as the degree to which it depends on capital from external sources. The trade measure used here which we will call trade extraversion is the value of exports of goods and services as a percentage of gross domestic product of 1965 . The foreign investment measure, overall foreign investment by the square root of kilowatt hours multiplied by population. It is for 1967. Hypothesis 1 expresses the expectation that both of these measures should be positively associated with disarticulation in the cross-section and positively associated with its increase over time as well.

Urban primacy: Urban primacy is conceptualized as the degree to which the 1st city of a national urban system stands out in both influence and population. It is measured simply in terms of population as the population of the total urban population residing in the largest city. Data on both urban population and largest cities, actually urban agglomerations with $>100,000$ people are from United Nations (1999a, b). The definition of urban is the nation definition, used on grounds that the typical features of urbanism vary so much that what may appear urban in one country need not be in another (Davis, 1979). Hypothesis 2 expresses the expectation that urban primacy will be positively associated with disarticulation in the cross-section as well as with increase in disarticulation over time.

Economic development: Economic development is measured as GNP, logged to correct for skewness. Data are from the World Bank (2007). Hypothesis 3 expresses the expectation that this indicator should have a curvilinear association with levels of disarticulation and with changes in disarticulation over time.

Percentage of the labor force in agriculture: Data on the percentage of the labor force in agriculture in 1965 and 1980 are from the World Bank (2007). Hypothesis 4 leads to an expectation that this indicator should be positively associated with disarticulation in the cross-section and that change in this indicator should be positively associated with change in disarticulation over time.

\section{RESULTS AND DISCUSSION}

Hypotheses 1 and 2, the ones from the dependency literature are primarily about developing countries. Hypotheses 3 and 4 from the modernization literature are about all nations. They all have implications about associations among national level variables at one point over time. Table 1 and 2 show cross-sectional and panel associations with disarticulation, respectively for all nations, peripheral nations and less developed nations as defined by criterion of a gross national product of $\$ 1500$ or less in 1975. Examination of Table 1 for cross-sectional analyses around 1975, suggests some support for both the dependency and the modernization views of disarticulation offered above with the dependency view appearing to fare a bit better.

Equation 1 for instance, suggests no support for the modernization view, expressed in hypothesis 4 that the percentage of the labor force in agriculture is positively associated with disarticulation. Still, both hypotheses 1 and 2 from the dependency perspective fare very well in the cross-sectional analysis. Equation 2 and 3 indicate that both measures of a nation's extraversion, overall foreign investment and trade extraversion are strongly and positively associated with disarticulation when only GNP per capita (logged) is controlled. Moreover, Eq. 4 
J. Econ. Theroy, $5(1): 22-27,2011$

Table 1: Regression of disarticulation in 1965 on various combination of independent variables (Standard regression coefficients)

\begin{tabular}{|c|c|c|c|c|c|c|c|c|c|}
\hline \multirow[b]{2}{*}{ Independent variables } & \multicolumn{9}{|c|}{ Equations } \\
\hline & 1 & 2 & 3 & 4 & 5 & 6 & 7 & 8 & 9 \\
\hline Labor force in agriculture (\%) & & & & & 0.76 & $0.57^{*}$ & $0.49^{*}$ & 0.37 & 0.29 \\
\hline GNP per capita (logged) & -1.31 & $-0.41 * * * *$ & $-0.40^{* * * * *}$ & $-0.27^{* *}$ & 0.30 & 0.23 & 0.17 & 0.10 & -0.17 \\
\hline Square of logged & 0.91 & & & & & & & & \\
\hline \multicolumn{10}{|l|}{ GNP per capita } \\
\hline Overall foreign investment & & $0.30^{\text {*** }}$ & & & & 0.16 & & 0.13 & 0.19 \\
\hline Trade extraversion & & & $0.31^{* * *}$ & & & & & 0.12 & \\
\hline Urban primacy & & & & $0.42^{\text {***** }}$ & & $0.35^{\text {**** }}$ & $0.38^{* * *}$ & $0.48^{\text {*** }}$ & $0.48^{* * *}$ \\
\hline $\mathrm{N}$ & 79.00 & 76.00 & 74.00 & 66.00 & 77.00 & & & & \\
\hline $\mathrm{R}^{2}$ & 0.16 & 0.25 & 0.25 & 0.31 & 0.25 & & & & \\
\hline
\end{tabular}

shows that urban primacy is also strongly and positively associated with disarticulation under the same circumstances. In the most complete equations, Eq. 6 and 7 the two measures of extraversion are no longer significantly associated with disarticulation, even though both the percentage of the labor force in agriculture and urban primacy are significantly associated with disarticulation. It is very likely however that the proper interpretation of this latter finding is not that extra version has had no effect upon disarticulation but that its effect has been mediated by its effect on urban primacy.

Such an interpretation is consistent with London (1987)'s finding. Equation 8 and 9 show that among peripheral and less developed nations only urban primacy has a significant controlled association with disarticulation in the cross-section, a result that again accords better with its modernization counterpart. The picture becomes more complicated when we turn to the panel analysis shown in Table 2. Equation 1 and 2 represent the most complete models in which all variables retain a significant association with change in disarticulation between 1965 and 1980. Notably absent from this model is urban primacy which shows no significant association with such change in any model investigated for this study however, simple. Three findings stand out in equations 1 and 2 and they all cast enormous doubt upon the dependency view of disarticulation while providing support for the modernization perspective. The first is that the coefficients for GNP per capita (logged) and its square are both significant and in the directions predicted by hypothesis 3 . It would seem that less developed nations were likely to experience increases in disarticulation and more developed ones, decreases in the period from 1965-1980. Secondly, the positive and significant coefficient for growth in the labor force associated with agriculture between 1965 and 1980 suggests that those nations experiencing a decrease in this component of their labor forces were most likely to experience decreases in disarticulation as well.
Table 2: Panel regression of disarticulation in 1980 on itself and other variables around 1965 standardized regression coefficients

\begin{tabular}{|c|c|c|c|c|}
\hline $\begin{array}{l}\text { Independent } \\
\text { variables }\end{array}$ & $\begin{array}{l}\text { All nations } \\
\text { (1) }\end{array}$ & $\begin{array}{l}\text { Peripheral } \\
\text { (2) }\end{array}$ & $\begin{array}{l}\text { Less nations } \\
\text { (3) }\end{array}$ & $\begin{array}{l}\text { Developed } \\
\text { nations (4) }\end{array}$ \\
\hline $\begin{array}{l}\text { Disarticulation } \\
\text { (1965) }\end{array}$ & $0.90^{* * * *}$ & $0.91^{* * * * *}$ & $0.88^{* * * * *}$ & $0.92^{* * * * * *}$ \\
\hline $\begin{array}{l}\text { Change in \% } \\
\text { labor force } \\
\text { agriculture }\end{array}$ & $0.22^{* * * *}$ & $0.21^{* * * * *}$ & $0.33^{* * * * *}$ & $0.33^{\text {***** }}$ \\
\hline $\begin{array}{l}\text { GNP per capita } \\
\text { (logged) }\end{array}$ & $1.97^{*}$ & $2.32^{* * *}$ & $0.15^{*}$ & $0.21^{* * *}$ \\
\hline $\begin{array}{l}\text { Square of logged } \\
\text { GNP per capita }\end{array}$ & $-2.03^{*}$ & $-2.35^{* * *}$ & - & - \\
\hline $\begin{array}{l}\text { Overall foreign } \\
\text { investment }\end{array}$ & $-0.13^{*}$ & & $-0.17^{* * *}$ & $-0.16^{*}$ \\
\hline Trade extraversion & - & -0.10 & - & - \\
\hline $\mathrm{N}$ & 73.00 & 71.00 & 37.00 & 45.00 \\
\hline $\mathrm{R}^{2}$ & 0.82 & 0.84 & 0.84 & 0.83 \\
\hline
\end{tabular}

Indicates association significant at 0.05 level; *** at 0.01 level and $* * * a t$ 0.001 level

This is consistent with the hypothesis 4 . Third and perhaps most unexpected is the negative and significant controlled association between overall foreign investment growth in disarticulation 1965 and 1980 (The association with trade extraversion is also negative though it is not statistically significant). This finding flies in the face of hypothesis 1 is much more consistent with the modernization view that capital, whatever its source will tend to diminish disarticulation beyond a certain point in the development process. The most puzzling findings shown in Table 2 , however call into question the beyond a certain point qualifier, since as Eq. 3 and 4 suggest the controlled association between overall foreign capital and disarticulation is significantly negative, even for peripheral and less developed nations. The real question one faces after the kind of equivocal analyses presented in this study is whether one dares to trust the results of apparently contradictory here, more than anything else are what stand out. The cross-sectional analyses, involving $>70$ nations around 1965 provide evidence that nations with the greatest amounts of sectoral disarticulation as the concept is measured here were in fact the ones that were extraverted or economically dependent on the outside world and 
especially, ones whose populations had flocked to primate cities where the lights of that outside world shone most brightly. These analyses appear to support the dependency position developed originally by Amin (1974, 1976) and adumbrated by Stokes and Anderson (2000) and Huang (1995). The panel analyses also involving $>70$ nations however, appear to tell another story. This is a story that is much more consistent with the modernization version of disarticulation presented in this study. This version sees disarticulation as being part of a normal transitional stage of development, a stage characterized by early capital investment in one or a few economic sectors but a stage that most nations pass through as working populations move from less developed sectors to more developed ones and as capital investments are made more equitably across all sectors. It is also a version that sees foreign capital investment as having potentially articulating as well as disarticulating, effects that is of creating conditions that are conducive to more even development as well as uneven development among various economic sectors. The evidence from the cross-sectional analyses does suggest that extraversion of various sorts and urban primacy perhaps engendered by such extraversion were partly responsible for differences in 1965 levels of structural disarticulation, especially in less developed countries.

My personal reading of the dependency and modernization positions, however is that they are both primarily concerned with the societal processes associated with increasing or decreasing disarticulation, rather than with predictors of the extent to which disarticulation may exist in a society. In other words, we think both positions are amenable to the view that the particular historical circumstances of individual nations may include a history of colonization and/or decolonization, political strife and resource discovery and/or utilization.

\section{CONCLUSION}

As a result, we are inclined to believe that panel, rather than cross-sectional analyses because of their capacity to focus on the factors contributing to short-term change may be the more appropriate tests for differences in the two perspectives. If this is so, the modernization perspective would seem to fare better here. Certainly if this is so, it is not reason for complacency on the part of government planners in developing nations. Disarticulation is almost surely associated with delays in equitable distribution of social benefits associated with development and efforts to hasten its diminution as well as to alleviate its problematic effects are probably well directed.

\section{RECOMMENDATIONS}

We would like to close, however with some serious caveats about the current analysis and suggestions for future ones related to disarticulation. Most important, we will like to attest to the exploratory nature of this analysis. Though, we hope to set the stage for subsequent investigations into the determinants of economic disarticulation because of the conviction that all models of addressing possible determinants are about process we have devised a measurement of disarticulation that unlike earlier ones can be used to track change over time. We are nonetheless aware that the measure remains reasonably crude and is susceptible to improvement. Moreover, the current models are relatively simple and can hardly be said to take account of all variables that affect developing countries today.

Thus, for instance while this analysis focused on variables that seem appropriate to the period between 1965 and 1980, a case can be made that kinds of dependency measured here would be less appropriate for studying changes in disarticulation today when foreign debt and structural adjustments to that debt may be at least as important as levels of external trade and foreign investment. Still, the investigation of the determinants of disarticulation has begun and it is begun with a reminder that we perhaps should not forget as we go on to take into account the possibility that disarticulation may be a largely unavoidable consequence of economic change and development.

\section{REFERENCES}

Amin, S., 1974. Accumulation on a World Scale: A Critique of the Theory of Underdevelopment. Vol. 1-2, Monthly Review Press, New York, ISBN-13: 9780853452720, pp: 666.

Amin, S., 1976. Unequal Development. Monthly Review Press, New York.

Ballmer-Cao, T., 2009. Compendium of Data for World System Analysis. Soziologishes Institute der Universitat Zurich, Zurich.

Davis, K., 1979. World Urbanization 1955-1970. Vol. 1: Basic Data For Cities, Countries and Regions. University of California Press, Berkeley.

Huang, J., 1995. Structural disarticulation and third world human development. Int. J. Comp. Soc., 36: 164-183.

Jacobs, J., 2004. Cities and the Wealth of Nations. Random House Publishing, New York.

Kuznets, S., 1955. Economic growth and income inequality. Am. Econ. Rev., 45: 1-28.

Lecaillion, J., 2004. Income Distribution and Economic Development: An Analytical Survey. International Labor Office, Geneva, Switzerland. 
London, B., 1987. Structural determinants of third world urban change: An ecological and political economic analysis. Am. Soc. Rev., 52: 28-43.

Nielsen, F., 1994. Income inequality and industrial development: Dualism revisited. Am. Soc. Rev., 59: 654-677.

Stokes, C. and P. Anderson, 2000. Theories and Measurement of Urban Primacy: A Critique. In: Urbanization in the World-Economy, Timberlake, $\mathrm{M}$. (Ed.). Academic Press, Orlando, pp: 87-120.
United Nations, 1999a. Trends and Prospects in Urban and Rural Population, 1950-2000. United Nations Publications, New York.

United Nations, 1999b. Trends and Prospects in the Populations of Urban Agglomerations, 1950-2000. United Nations Publications, New York.

World Bank, 2007. World Development Report 2007. Oxford University Press, New York. 